\title{
A Comparison of Alternative Tests of Contagion with Applications
}

\author{
Mardi Dungey, Renée Fry, Brenda González-Hermosillo, \\ and Vance L. Martin
}

\section{INTRODUCTION}

A common characteristic of asset markets during periods of crisis is that asset returns exhibit greater volatility than they do during noncrisis periods. One suggested mechanism to account for the increased volatility is transmissions due to contagion, and a number of empirical tests have been developed to try to identify this effect.

Forming a consensus on the empirical evidence for contagion in the existing literature is complicated by applications that differ by methodology, common factor specification, sample period selection, and asset market choice; see, for example, the overviews in Dornbusch, Park, and Claessens (2000) and Pericoli and Sbracia (2003). This chapter investigates these issues by making a comparison of four tests of contagion applied to common data sets and sample periods for three specific incidences of crisis in financial markets. The tests examined are the latent factor model of Dungey, Fry, González-Hermosillo, and Martin (2002, 2005; the DFGM test), the correlation approach of Forbes and Rigobon (2002; the FR test), the dummyvariable approach of Favero and Giavazzi (2002; the FG test), and the probability-based measure of Bae, Karolyi, and Stulz (2003; the BKS test).

The DFGM test is based on a linear latent factor model, where the parameters are identified by the change in volatility structure of returns

Dungey: Australian National University and CERF, mardi.dungey@anu.edu.au; Fry: Australian National University, renee.fry@anu.edu.au; González-Hermosillo; International Monetary Fund, bgonzalez@imf.org; Martin, vance@unimelb.edu .au. This project was funded under ARC large grant A00001350. We are grateful to Stuart Gourley for research assistance. This chapter was partly written while Mardi Dungey was a Visiting Fellow at CERF, and she thanks them for their hospitality. The views expressed in this chapter are those of the authors and do not necessarily represent those of the IMF or IMF policy. 
under the two regimes, noncrisis and crisis periods. The FR test is based on comparing the correlation of returns between assets across regimes. This test is initially presented as a bivariate test, but can be extended to a multivariate setting by embedding the approach into a regime model augmented by dummy variables, and simply performing a Chow test (Dungey et al. 2005). The FG test is based on the exceedances (outliers) in one country to represent crisis periods, and testing the significance of these dummies in the return equations of other countries to test for contagion. The BKS approach is related to the FG approach, with the main difference being that the explanatory variable is transformed to a polychotomous dummy variable to represent the number of countries experiencing a crisis.

The various tests of contagion can be viewed as alternative ways of testing the statistical significance of changes in the volatility of asset returns between noncrisis and crisis periods, having conditioned on common and idiosyncratic factors (Dungey et al. 2005). The key distinguishing feature of these tests, however, is the way that information is filtered during crisis periods to identify potentially contagious linkages. An important aim of this chapter is to determine whether these alternative filtering methods result in different conclusions by using a range of common data sets. The tests are applied to equity markets during the Mexican peso crisis of 1994-95 (Tequila effect), the Hong Kong speculative attack in October 1997 (Asian flu), and the Argentine crisis of 2001-02. In each case a sample of three countries is chosen. Three hypotheses are tested. The first (hypothesis 1) is an overall test of contagion allowing for linkages among all countries during a crisis period. Hypothesis 2 tests for contagion from one country (the host country) to both of the other countries in the sample. Hypothesis 3 tests for contagion between two individual countries. For the first two hypotheses, the results show that there is broad agreement for evidence of contagion among all test statistics. For the third hypothesis the evidence is more mixed.

The chapter is organized as follows. Section 2 outlines the four methods of testing for contagion. A number of empirical issues in implementing these tests are discussed in section 3, while section 4 sets out the steps for the practical application of each test. The tests are then applied in section 5. Concluding comments are given in section 6 .

\section{EMPIRICAL TESTS OF CONTAGION}

A relatively common means of representing asset returns in the finance literature is as a two-factor model. Let the return on the $i$ th asset in a noncrisis period be represented by $x_{i, t}$, while the corresponding return on the asset during a crisis period is given by $y_{i, t}$. The durations of the noncrisis and crisis samples are, respectively, $T_{x}$ and $T_{y}$. During periods of calm a standard two-factor model is assumed, in that the return in each market is a linear function of a set of common shocks $\left(w_{t}\right)$, which affect all asset markets, and an idiosyncratic shock $\left(u_{i, t}\right)$. For a set of $N$ asset markets, this relationship is represented as 


$$
x_{i, t}=\lambda_{i} w_{t}+\delta_{i} u_{i, t^{\prime}} \quad i=1,2 \ldots N,
$$

where $\lambda_{i}$ and $\delta_{i}$ are the loadings on the common factor and the idiosyncratic factor, respectively. For certain classes of models the common shocks represent the market fundamentals while the idiosyncratic shocks correspond to periods where actual returns deviate from the market fundamental values.

Crisis periods are commonly characterized as periods of increased volatility in asset returns, whereby the variance of $y_{i, t}$ is greater than the variance of $x_{i, t}$. This may be due to increased volatility in either the common shocks or the idiosyncratic shocks, or the result of additional channels that may arise only during crisis periods. It is this last channel which is commonly referred to as contagion (e.g., Kaminsky, Reinhart, and Végh, this volume; Masson 1999; Forbes and Rigobon 2002). That is, in the measurement of contagion any increases in volatility would necessarily exclude increases in either the volatility of the common shocks $w_{t}$, or increases in the volatility of the idiosyncratic shocks $u_{i, t}$ or both. To allow for potentially contagious transmission mechanisms during financial crises, it is necessary to augment equation (1) by including additional contagion variables when modeling returns in crisis period $y_{i, t}$.

\subsection{The DFGM Test}

The Dungey, Fry, González-Hermosillo, and Martin $(2002,2005)$ contagion test (DFGM) is based on modeling contagion as the transmission of idiosyncratic shocks across asset markets. This involves extending the noncrisisperiod asset returns equation in (1) to

$$
y_{i, t}=\lambda_{i} w_{t}+\delta_{i} u_{i, t}+\sum_{j=1, j \neq i}^{N} \gamma_{i} \mu_{j t}, \quad i=1,2 \ldots N,
$$

where the $x_{i, t}$ is replaced by $y_{i, t}$ as the model is defined for the crisis period. The term $\gamma_{i, j} u_{j, t}$ represents the effect of a shock in asset $j$ at time $t$ transmitted to the returns of asset $i$. To test the null hypothesis of no contagion in all asset markets amounts to a joint test of $\gamma_{i, j}=0$ for all $i, j, i \neq j$.

In performing the DFGM test, the world shocks are treated as a latent factor. The simplest representation is given by specifying $w_{t}$ to be independently and identically distributed with zero mean and unit variance

$$
w_{t} \sim \text { i.i.d. }(0,1) \text {. }
$$

To complete the specification of the model, the idiosyncratic shocks are also assumed to be

$$
u_{i, t} \sim \text { i.i.d. }(0,1) \text {. }
$$

The assumptions on the factors mean that the difference in the volatility of the $i$ th asset return between crisis and noncrisis periods is solely due to contagion, where 


$$
E\left[y_{i, t}^{2}\right]-E\left[x_{i, t}^{2}\right]=\sum_{j=1, j \neq i}^{N} \gamma_{i, j}^{2} .
$$

A more general specification is to let the common factor exhibit autocorrelation and a GARCH volatility structure; see Dungey and Martin (2004). This property is particularly important when using high-frequency asset returns data as the conditional volatility structures of asset returns tend to exhibit common features that can be parsimoniously modeled within a latent factor structure (Dungey et al. 2002).

The DFGM test is implemented by equating the theoretical moments as derived from equations (1) to (4) with the empirical moments from the sample data. The estimation is based on Generalized Method of Moments (GMM). For example, when the number of assets $N=3$, the number of unknown loading parameters in equations (1) and (2) is 12 . These parameters can be uniquely identified from the variance-covariance matrix of the asset returns in the precrisis and crisis periods, as both matrices contain six unique moments, yielding a total of twelve empirical moments. For this model a test of contagion amounts to testing the overidentifying restrictions arising from setting the relevant $\gamma_{i, j}$ parameters in equation (2) to zero.

\subsection{The FR Test}

The Forbes and Rigobon (2002) test is based on testing the (unconditional) correlations between pairs of asset returns in the crisis and noncrisis periods. The common shocks $w_{t}$ in equation (2) are modeled using a vector autoregression (VAR), augmented by additional control variables, with the residuals representing the idiosyncratic factors. In computing the unconditional correlation in the crisis period, an adjustment factor is introduced to allow for any increases in asset return volatility arising from increases in the volatility of the factors in equation (1).

To test for contagion from one asset market, the host market, to another asset market using the FR test, the FR test statistic is

$$
\mathrm{FR}=\frac{\frac{1}{2} \ln \left(\frac{1+v_{y}}{1-v}\right)-\frac{1}{2} \ln \left(\frac{1+\rho_{x}}{1-\rho_{x}}\right)}{\sqrt{\frac{1}{T_{y}-3}+\frac{1}{T_{x}-3}}},
$$

where $\rho_{x}$ is the correlation coefficient between the two asset returns in the noncrisis period. Forbes and Rigobon (2002) define the noncrisis period as the total sample. The unconditional correlation coefficient in the crisis period, $v_{y^{\prime}}$ is adjusted to account for the higher volatility in that period using

$$
v_{y}=\frac{\rho_{y}}{\sqrt{1+\left(\frac{\sigma_{y, i}^{2}-\sigma_{x, i}^{2}}{\sigma_{x, i}^{2}}\right)\left(1-\rho_{y,}^{2}\right)}},
$$


where $\rho_{y}$ is the correlation between two asset returns in the crisis period, and $\sigma_{x, i}^{2}$ and $\sigma_{y, i}^{2}$ are, respectively, the variances of the asset returns in the noncrisis and crisis periods of the $i$ th (host) asset returns. ${ }^{1}$

An alternative way to represent the FR test is to express it as a Chow test (Dungey et al. 2005). This has the advantage that it provides a natural framework in which to generalize the FR test to allow for multivariate versions of the test as well as correcting for endogeneity bias. For the bivariate problem, the approach is based on the following regression equation:

$$
\left(\frac{z_{2, t}}{\sigma_{x, 2}}\right)=\gamma_{0}+\gamma_{1} d_{t}+\gamma_{2}\left(\frac{z_{1, t}}{\sigma_{x, 1}}\right)+\gamma_{3}\left(\frac{z_{1, t}}{\sigma_{x, 1}}\right) d_{t}+\eta_{t \prime}
$$

where

$$
z_{i}=\left(x_{i, 1}, x_{i, 2} \ldots x_{i, T_{x}} \quad y_{i, 1}, y_{i, 2}, \ldots y_{i, T_{y}}\right)^{\prime}, \quad i=1,2
$$

represents the $\left(T_{x}+T_{y}\right) \times 2$ scaled pooled data set by stacking the precrisis and crisis scaled data with $T_{x}$ and $T_{y}$ observations, respectively. The dummy variable, $d_{t}$, is defined as

$$
d_{t}= \begin{cases}1: & t>T_{x} \\ 0: & \text { otherwise, }\end{cases}
$$

and $\sigma_{x, i}$ is the standard deviation of the $i$ th asset returns during the noncrisis period and $\eta_{t}$ is an error term. The test of contagion is based on testing $\gamma_{3}=0$ in equation (8). Rewriting the FR test as in equation (8) shows that contagion is modeled by the additional contemporaneous effects of $y_{1, t}$ on $y_{2, t}$ in the crisis period.

\subsection{The FG Test}

The Favero and Giavazzi (2002) test of contagion is based on modeling increases in volatility during the crisis period in one asset market by the extreme movements in the asset returns of other markets. To highlight the approach, consider a bivariate version $(N=2)$ of the crisis period model in equation (2):

$$
\begin{aligned}
& y_{i, t}=\lambda_{i} w_{t}+\delta_{i} u_{i, t} \\
& y_{j, t}=\lambda_{j} w_{t}+\delta_{j} u_{j, t}+\gamma u_{i, t \prime}
\end{aligned}
$$

where a test of contagion is given by the impact of $u_{i, t}$ on $y_{j, t}$ a test of $\gamma=0$. The FG approach is to replace the $u_{i, t}$ in equation (12) by a set of dummy variables representing points in time when an asset market experiences an extreme movement, as follows:

$$
\begin{aligned}
& y_{i, t}=\lambda_{i} w_{t}+\delta_{i} u_{i, t^{\prime}} \\
& y_{j, t}=\lambda_{j} w_{t}+\delta_{j} u_{j, t}+\sum_{k=1}^{K} \gamma_{i, k} d_{i, k, t}
\end{aligned}
$$


where $d_{i, k, t}$ represent the $K$ extreme observations associated with $y_{i, t}$, defined as

$$
d_{i, k, t}= \begin{cases}1: & \left|e_{i, t}\right|>\mathrm{THRESH}_{i} \\ 0: & \text { otherwise }\end{cases}
$$

where $e_{i, t}$ is taken as the residuals from a VAR containing all variables in the

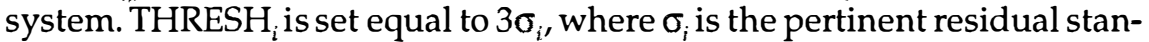
dard deviation of equation $i$ of the VAR. The dummy variables are also commonly referred to as exceedances.

The FG test contrasts with the DFGM and FR tests where the latter tests use all information during the crisis period, not just the extreme values, to test for contagion. The test of contagion is a test of the parameter $\gamma_{i, k}$. FG, in defining $w_{t}$, include the exceedances of all other countries. Further, the FG test requires specifying the common factor as consisting of own lagged returns and contemporaneous returns on the other assets. This choice is partly governed by identification issues. For a bivariate system the model is just identified with estimation based on an instrumental variables (IV) procedure. However, as asset returns exhibit very little autocorrelation, identification of the model may be problematic. This may manifest itself into a weak instrument problem resulting in the moments of the sampling distribution being undefined and in inflated standard errors. These identification issues do not arise for the DFGM test, as the common factor is modeled explicitly as a latent factor that is identified by information on the returns in all asset markets. In contrast, endogeneity issues are not taken into account in the FR test in equation (6), which suggests that this test statistic is likely to be affected by endogeneity bias.

\subsection{The BKS Test}

As with the Favero and Giavazzi (2002) contagion test, Bae, Karolyi, and Stulz (2003) focus on the effects of extreme shocks in one asset market on another asset market using exceedances. The exceedance in asset market $i$ in their approach is defined as

$$
d_{i, t}= \begin{cases}1: & \left|y_{i, t}\right|>\text { THRESH }_{i} \\ 0: & \text { otherwise, }\end{cases}
$$

where $\mathrm{THRESH}_{i}$ is set to capture the 5 percent tail of large positive and negative values. Baur and Schulze (2003) extend this to consider a number of different thresholds endogenously. Unlike the FG test, there is only a single exceedance variable for each asset market. Once the exceedances have been identified, the co-exceedances between shocks originating from asset $i$ and asset $j$ are constructed when

$$
d_{i, t} d_{j, t}=1
$$

For $N$ asset markets, categorizing asset returns into coexceedances yields a polychotomous variable that gives the number of coexceedances occurring 
at each point in time. A multinomial logit framework is then used to model the coexceedances as

$$
P_{j, t}=\frac{\exp \left(\beta_{j} x_{j, t}\right)}{\sum_{k=0}^{N} \exp \left(\beta_{k} x_{k, t}\right)}, j=0,1,2, \ldots N,
$$

where $P_{j, t}$ is the probability that there are $j$ co-exceedances occurring at time $t$, and $x_{j, t}$ represents a set of explanatory variables used to explain asset returns and hence the co-exceedances. The model is normalized by setting $\beta_{0} \equiv 0$, which corresponds to the case of no exceedances (i.e., no outliers).

The BKS contagion test consists of specifying the exceedances/coexceedances of other sets of countries in the set of explanatory variables, given by $x_{j, t}$ in equation (18), and testing the joint significance of the corresponding parameters. To test for contagion within a region of three countries, for example, the co-exceedance variable is initially constructed for a pair of countries (the $j$ th and $k$ th) with the polychotomous variable consisting of the values $0,1,2$. The exceedance of the remaining country (the $i$ th) is then constructed and included in the set of explanatory variables. The BKS contagion test is then a test of the significance of the $i$ th exceedance variable in explaining the $j$ th and $k$ th co-exceedances.

A special case of the BKS contagion test is the approach of the Eichengreen, Rose, and Wyplosz $(1995,1996)$, who test for significant correlations between extreme movements in asset returns by creating a binary variable for the presence or otherwise of domestic and international crises as leftand right-hand-side variables, respectively. As noted above, the BKS and FG tests are similar in that both tests amount to testing the significance of the effects of extreme observations in one market, or set of markets, on another asset market. One obvious difference between the two approaches is that the BKS test uses information on co-exceedances in measuring contagion, whereas the FG test uses co-exceedances as conditioning information. Part of the reason for this is the way in which Favero and Giavazzi (2002) construct their exceedance variables - namely, assigning a separate dummy variable to each extreme observation.

\section{ADDITIONAL EMPIRICAL ISSUES}

\subsection{Identifying Crisis Periods}

A particularly difficult problem in the financial contagion literature is the choice of sample period; see, for example, Kaminsky and Schmukler (1999) and Jacobs, Kuper, and Lestano (this volume). Most authors wish to identify the period during which the financial markets are in crisis, and in some cases compare the crisis period with a clear noncrisis period. The literature on early warning systems (see Goldstein, Kaminsky, and Reinhart 2000) attempts to predict vulnerability to crises, although such indicators do not have a strong record in correctly predicting crisis events (Edison 2003; Berg 
and Pattillo 1999). Ideally, a systematic means of choosing crisis dates would result in a consistent set of dating conventions. In practice, however, this does not occur.

The choice of both crisis and noncrisis periods is almost always ad hoc, although often the sample selection is based on ex post rationalizations, making it difficult to compare studies, even those apparently conducted on the same crisis. This complicates comparisons across different studies, as variations in the outcomes are jointly determined by methodological and sample differences. Examples of ad hoc, ex post rationalizations of period choice are found in Forbes and Rigobon (2002) and Dungey et al. (2002). Glick and Rose (1999) and Van Rijckeghem and Weder (2001) use judgments based on newspaper and International Monetary Fund (IMF) staff views to determine whether contagion exists. Kaminsky and Schmukler (1999) also use news-based data to determine the dating of crises.

The alternate course taken in the literature is to use the sample data to identify the crisis periods compared with tranquil periods. This is most commonly through some form of threshold approach, such as found in Eichengreen, Rose, and Wyplosz (1995, 1996); Lowell, Neu, and Tong (1998); Favero and Giavazzi (2002); and Bae, Karolyi, and Stulz (2003). ${ }^{2}$

To further compound the difficulties in dating crises consistently, there are several obstacles to overcome. First, crises are typically quite short in duration. Second, there are a number of periods when multiple crises occur in quick succession-for example, the Russian bond default in mid1998 and the Long-Term Capital Management (LTCM) near-collapse in August-September 1998. Third, the starting point of a crisis is often associated with a large shock, such as the float of the Thai baht in July 1997, but the endpoint of the crisis is far more difficult to determine.

Productive future work would be to find a more objective procedure for dating crises in high-frequency data based on the data characteristics. However, any of the frameworks discussed above for testing contagion could in theory be extended to allow for endogenous breaks; see Dungey et al. (2005).

\subsection{Data Frequency, Missing Observations, and Time Zone Issues}

Most studies of contagion aim to control for the influence of fundamentals. Data for many of the fundamental variables are available only at relatively low frequency; for example, Eichengreen, Rose, and Wyplosz $(1995,1996)$. For this reason there are two distinct streams in the literature. The first contains those that consider relatively low-frequency data, including Glick and Rose (1999) and Van Rijckeghem and Weder (2001), which have the advantage of directly incorporating fundamental variables, such as trade and banking flows. The second involves high-frequency data, and represents the majority of the empirical work, including the correlation studies, most of the threshold models, and the latent factor models. An important difference between the two streams is that the high-frequency studies tend to consider contagion as a relatively short-lived feature, whose extremes would not be captured in lower frequency applications. 
In moving to higher frequency observations, two common problems emerge: missing observations and time zone alignment. Missing observations cause problems in tracking volatility across markets at time $t$. This can be dealt with in the following ways: replacing the missing observation with the previous market observation, interpolating between observations, or removing that data point from the investigation. In practice, only the first and last of these is considered, as interpolating volatile data would defeat the point of tracking the changes. The advantage of simple replacement is that it maintains a longer data series, but with the downside of changing the way in which shocks are presumed to track through the different countries. The alternative of simply deleting the missing observations may reduce information on the dynamics of that process. In practice, most researchers seem to adopt a strategy of deleting missing observations, and this is the strategy adopted in the empirical application of this chapter.

The time zone alignment problem occurs because, although markets are open on nominally the same date, there may be no actual trading-time overlap, such as occurs for Argentina and Indonesia. Events in Indonesia at observed date $t$ can be processed by Argentinean markets on date $t$ also. However, events occurring on date $t$ in Argentina cannot be absorbed by Indonesian markets until date $t+1$. This problem is most severe for equity markets where local trade-closing data are often used; see, for example, the contemporaneous and day-after correlations between equity market returns provided in Kaminsky and Reinhart (2003).

There are a number of ways to deal with time zone problems. One approach is to control for differences in time zones by using moving averages of returns (e.g., Forbes and Rigobon 2002). A drawback of this strategy is that it may mask some of the movements in asset prices, and potentially introduce spurious dynamics into the relationships among asset returns via the moving-average filter. Kaminsky and Reinhart (2003) test the significance of dummy variables that reflect time zone differences and show there are discernible differences. Bae, Karolyi, and Stulz (2003) choose different lags depending on the time zone and causal patterns studied. For the more general case where the timing of domestic market trading times overlap, simulation methods may be a useful approach. ${ }^{3}$ The importance of correctly matching the timing of financial market data is highlighted by Taylor (1987) and more recently by Knif and Pynnonen (1999).

\section{NUMERICAL PROCEDURES}

In this section, numerical procedures for implementing contagion tests are presented. In each application there are $N=3$ countries. All programs are written in GAUSS v.5.0.1, with computer codes available from the first author's Web site.

Before implementing the DFGM, FR, and BKS tests, the returns are filtered by estimating a VAR with one lag, with U.S. returns as a control vari- 
able. The residuals represent the filtered returns in the calculations that follow for these tests. This filtering is not conducted for the FG test, to be commensurate with their methodology. For the Tequila crisis and Argentine crisis, U.S. returns at time $t$ are used. For the Asian flu, the U.S. returns are dated at time $t-1$ to allow for time zone effects.

\subsection{The DFGM Test}

Step 1: Estimate the following unconstrained system of equations by GMM:

$$
\begin{aligned}
& x_{i, t}=\lambda_{i} w_{t}+\delta_{i} u_{i, t} \quad i=1,2,3, \\
& y_{i, t}=\lambda_{i} w_{t}+\delta_{i} u_{i, t}+\sum_{j=1, j \neq i}^{3} \gamma_{i, j} u_{j, t \prime} \quad i=1,2,3 .
\end{aligned}
$$

The system is just identified as there are twelve empirical moments based on the variances and covariances for the noncrisis and crisis periods, and twelve unknown parameters $\left(\lambda_{1}, \lambda_{2}, \lambda_{3}, \delta_{1}, \delta_{2}, \delta_{3}, \gamma_{1,2}\right.$ $\gamma_{1,3}, \gamma_{2,1}, \gamma_{2,3}, \gamma_{3,1}$, and $\gamma_{3,2}$ ).

Step 2: Contagion tests are performed by using a Wald test on the contagion parameters $\left(\gamma_{i, j}\right)$.

\subsection{The FR Test}

\subsubsection{Bivariate FR Test}

Step 1: Compute the unconditional correlation between two returns over the precrisis period $\left(\rho_{x}\right)$.

Step 2: Compute the unconditional correlation $\left(v_{y}\right)$ between two returns over the total period based on equation (7).

Step 3: Compute the FR test statistic given in equation (6).

Step 4: Perform a one-sided test of the null hypothesis $v_{y}=\rho_{x}$ against the null of $v_{y}>\rho_{x}$, indicating contagion.

\subsubsection{Multivariate FR Test}

Step 1: Construct the dummy variable $\left(d_{t}\right)$ in equation (10).

Step 2: Estimate the following system of equations:

$$
\begin{aligned}
\left(\frac{z_{1, t}}{\sigma_{x, 1}}\right)= & \gamma_{1,0}+\gamma_{1,1} d_{t}+\gamma_{1,2}\left(\frac{z_{2, t}}{\sigma_{x, 2}}\right)+\gamma_{1,3}\left(\frac{z_{3, t}}{\sigma_{x, 3}}\right)+\gamma_{1,4}\left(\frac{z_{2, t}}{\sigma_{x, 2}}\right) d_{t} \\
& +\gamma_{1,5}\left(\frac{z_{3, t}}{\sigma_{x, 3}}\right) d_{t}+\eta_{1, t} \\
\left(\frac{z_{2, t}}{\sigma_{x, 2}}\right)= & \gamma_{2,0}+\gamma_{2,1} d_{t}+\gamma_{2,2}\left(\frac{z_{1, t}}{\sigma_{x, 1}}\right)+\gamma_{2,3}\left(\frac{z_{3, t}}{\sigma_{x, 3}}\right)+\gamma_{2,4}\left(\frac{z_{1, t}}{\sigma_{x, 1}}\right) d_{t} \\
& +\gamma_{2,5}\left(\frac{z_{3, t}}{\sigma_{x, 3}}\right) d_{t}+\eta_{2, t}
\end{aligned}
$$




$$
\begin{aligned}
\left(\frac{z_{3, t}}{\sigma_{x, 3}}\right)= & \gamma_{3,0}+\gamma_{3,1} d_{t}+\gamma_{3,2}\left(\frac{z_{1, t}}{\sigma_{x, 1}}\right)+\gamma_{3,3}\left(\frac{z_{2, t}}{\sigma_{x, 2}}\right)+\gamma_{3,4}\left(\frac{z_{1, t}}{\sigma_{x, 1}}\right) d_{t} \\
& +\gamma_{3,5}\left(\frac{z_{2, t}}{\sigma_{x, 2}}\right) d_{t}+\eta_{3, t}
\end{aligned}
$$

Step 3: Perform Wald tests for contagion on the parameters $\gamma_{i, 4}$ and $\gamma_{i, 5^{*}}$

\subsection{The FG Test}

Step 1: Estimate a VAR on returns over the total period and identify dummy variables corresponding to outliers in the residuals based on equation (15).

Step 2: Classify local shocks for each asset return $\left(d_{1, j, t}, d_{2, j, t,}, d_{3, j, t} ;\right.$ i.e., where there is an outlier that is unique to that asset return at a point in time). Let the number of local shocks for each asset return be $M$, $N$, and $P$, respectively.

Step 3: Classify dummy variables into $K$ global shocks, $d_{c, k, t}$, where the $c$ subscript denotes common shocks (i.e., where there is an outlier in at least two asset returns at time $t$ ).

Step 4: Estimate the following structural model by instrumental variables:

$$
\begin{aligned}
y_{1, t}= & \alpha_{1 t}+\beta_{1} y_{1, t-1}+\delta_{1,1} y_{2, t}+\delta_{1,2} y_{3, t}+\sum_{k=1}^{K} \gamma_{1, k} d_{c, k, t}+\sum_{j=1}^{M} \gamma_{1,1, j} d_{1, j, t} \\
& +\sum_{j=1}^{N} \gamma_{1,2, j} d_{2, j, t}+\sum_{j=1}^{P} \gamma_{1,3, j} d_{3, j, t}+e_{1, t^{\prime}} \\
y_{2, t}= & \alpha_{2 t}+\beta_{2} y_{2, t-1}+\delta_{2,1} y_{1, t}+\delta_{2,2} y_{3, t} \sum_{k=1}^{K} \gamma_{2, k} d_{c, k, t}+\sum_{j=1}^{M} \gamma_{2,1, j} d_{1, j, t} \\
& +\sum_{j=1}^{N} \gamma_{2,2, j} d_{2, j, t}+\sum_{j=1}^{P} \gamma_{2,3, j} d_{3, j, t}+e_{2, t^{\prime}} \\
y_{3, t}= & \alpha_{3 t}+\beta_{3} y_{3, t-1}+\delta_{3,1} y_{1, t}+\delta_{3,2} y_{2, t}+\sum_{k=1}^{K} \gamma_{3, k} d_{c, k, t}+\sum_{j=1}^{M} \gamma_{3,1, j} d_{1, j, t} \\
& +\sum_{j=1}^{N} \gamma_{3,2, j} d_{2, j, t}+\sum_{j=1}^{P} \gamma_{3,3, j} d_{3, j, t}+e_{3, t^{\prime}}
\end{aligned}
$$

where the instruments are the three lag returns. This system of equations is just identified.

Step 5: Perform likelihood ratio tests for contagion on the parameters $\gamma_{1,2, j}$ and $\gamma_{1,3, j}$ in the first equation in the system, $\gamma_{2,1, j}$ and $\gamma_{2,3, j}$ in the second equation in the system, and $\gamma_{3,1, j}$ and $\gamma_{3,2, j}$ in the third equation in the system.

\subsection{The BKS Test}

Step 1: Construct exceedances based on equation (17) for all asset returns. 
Step 2: For asset returns $i$ and $j$, classify the number of co-exceedances, ranging from $0,1,2$.

Step 3: Construct an indicator variable that is $I=0$ for no coexceedances in asset returns $i$ and $j, I=1$ for exceedances in asset $i$ but not asset $j, I=2$ for exceedances in asset $j$ but not asset $i$, and $l=3$, for co-exceedances in assets $i$ and $k$, where the indicator variable enters the likelihood function of equation (18).

Step 4: Estimate the multinomial logit model in equation (18), with the explanatory variables consisting of an intercept and the exceedances of asset $k$.

Step 5: Perform Wald tests on the parameter associated with the exceedances of asset return $k$.

Step 6: Repeat the tests for the other two combinations of asset returns.

\section{APPLICATIONS}

To illustrate the application of the empirical methodologies of contagion, three distinct crisis episodes in equity markets over the last decade are investigated. These are the so-called Tequila crisis associated with the float of the Mexican peso in December 1994; the speculative attack on the Hong Kong stock market in October 1997 during the East Asian financial crisis, the Asian flu; and the more recent problems in Latin America associated with Argentina in 2001.

Both the Mexican (Tequila) and Hong Kong (Asian flu) examples correspond to the bivariateexamples investigated in Forbes and Rigobon (2002), but are extended to a multivariate framework using additional contagion tests. These exercises illustrate the similarities and differences between the tests and the subsequent differences in the results that can be generated from the alternative tests, rather than provide definitive analysis of each of the crises. Here the aim is to provide an illustration of the implementation of the contagion methodologies outlined in the previous sections.

\subsection{Background}

Figure 1 illustrates the changes in volatility in equity markets over the three crises investigated in this chapter. The first column represents returns for Mexico, Argentina, and Chile during the Tequila crisis. The second column represents returns for Hong Kong, Korea, and Malaysia during the Asian flu. The final column represents returns for Argentina, Brazil, and Chile during the Argentine crisis. The reasons for the choice of sample periods and crisis subsamples are briefly described below.

\subsubsection{The Tequila Crisis: 1994-95 On 20 December 1994 the Mexican ex-} change rate band was widened and the peso devalued sharply. The peg was abandoned and the Mexican peso was allowed to float on 22 December 1994. Mexican financial markets melted down in the days that followed 

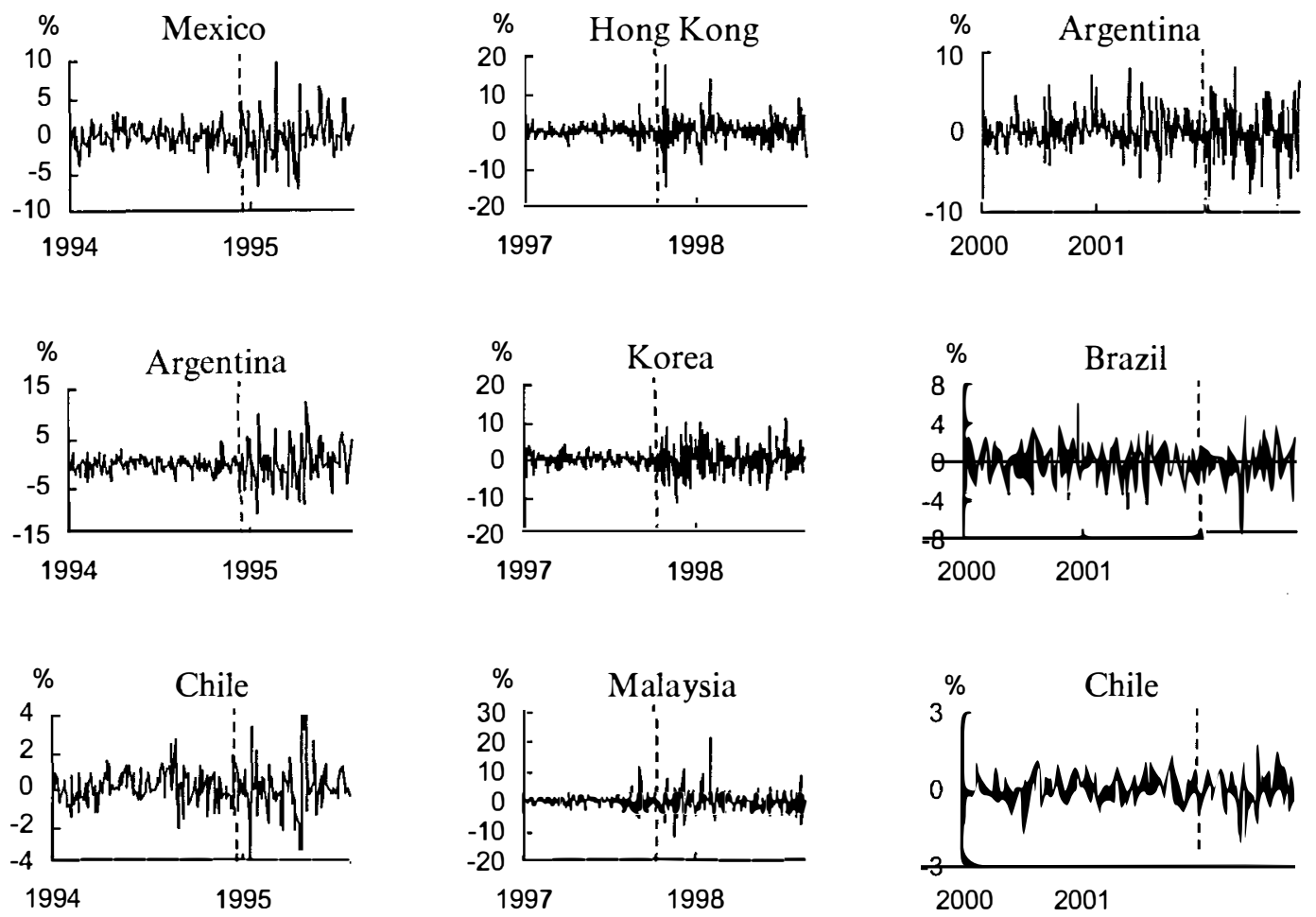

Fig. 1. Equity returns data for various crises: Tequila crisis (first column), Asian flu (second column), Argentine crisis (third column). The precrisis period in each figure is to left of the vertical dashed line, crisis period to the right. 
the currency attack as equity markets experienced extreme volatility, domestic interest rates soared, and banks came under pressure; see Sachs, Tornell, and Velasco (1996) for a chronology of the crisis. The Mexican crisis affected other emerging markets, particularly other Latin American countries, in what has been referred to as the Tequila crisis. Here we consider transmission between the equity markets of Mexico, Argentina, and Chile.

The sample period chosen here comprises a precrisis period from 1 June 1994 to 18 December 1994, and a crisis period of 19 December 1994 to 2 March 1995. This is a total sample of 197 observations, 143 in the precrisis period and 54 in the crisis period. The crisis date is not dissimilar to that examined by Forbes and Rigobon (2002), who date the crisis as beginning on 19 December 1994, but ending on 31 December 1994, which is earlier than the empirical example considered here. The end of the crisis period in this chapter corresponds to the period of reforms in the Mexican banking system.

The noncrisis period assumed in this study is shorter than that of Forbes and Rigobon (2002), and this is because it is not clear in the data or the chronology of the crisis that the earlier period in 1994 is less volatile than the designated crisis period assumed in this chapter. For example, Mexican financial markets were quite volatile in the aftermath of the assassination of the PRI's presidential candidate Colosio on 23 March 1994, when Mexico lost about one-third of its foreign reserves in a few weeks, the currency hit the ceiling of its intervention band, and domestic interest rates rose sharply.

Covariances and correlations for the Tequila crisis are shown in table 1. There is a marked increase in both variances and covariances, and corresponding increases in the correlation coefficients. Table 2 provides a decomposition of the variances of the equity returns in the precrisis and crisis periods into various components, based on the DFGM model estimated with GMM. ${ }^{4}$ In the precrisis period there is substantially diversifiable risk in Mexico and Chile, with the country factors contributing over 75 percent of total volatility. In the crisis period, both Mexico and Argentina experience substantial contagion effects, with evidence that the contagious links between these countries were reinforcing ( 66 percent of total volatility in Mexico is sourced as contagion from Argentina, and 75 percent of volatility in Argentina is sourced as contagion from Mexico).

5.1.2 The Asian Flu: 1997-98 Many East Asian currencies experienced rapid depreciation and high volatility during 1997, following the float of the Thai baht. In October 1997 the Hong Kong dollar experienced a speculative attack. This was successfully defended by its currency board. However, the turmoil translated into the equity market, which plunged dramatically over the period 20-23 October. This volatility was widely observed in other markets, including that of the United States, in the immediate aftermath of this speculative attack. Here we examine equity returns in Hong Kong, Korea, and Malaysia for the period from 1 January 
Table 1. Variances and Covariances (Correlations above Diagonal) of Daily Percentage Equity Returns for Selected Sample Periods

\begin{tabular}{|c|c|c|c|c|c|c|}
\hline & \multicolumn{3}{|c|}{ Precrisis Period } & \multicolumn{3}{|c|}{ Crisis Period } \\
\hline & (1) & (2) & (3) & (4) & (5) & (6) \\
\hline \multicolumn{7}{|c|}{ Tequila crisis } \\
\hline & Mexico & Argentina & Chile & Mexico & Argentina & Chile \\
\hline Mexico & 1.840 & 0.288 & 0.116 & 11.670 & 0.449 & 0.279 \\
\hline Argentina & 0.549 & 1.969 & 0.387 & 6.223 & 16.443 & 0.755 \\
\hline Chile & 0.118 & 0.408 & 0.363 & 1.150 & 3.695 & 1.457 \\
\hline
\end{tabular}

Asian flu

\begin{tabular}{lllllrr} 
& Hong Kong & Korea & Malaysia & Hong Kong & Korea & Malaysia \\
\cline { 2 - 6 } Hong Kong & 2.238 & 0.121 & 0.253 & 10.794 & 0.135 & 0.447 \\
Korea & 0.260 & 2.045 & 0.026 & 1.608 & 13.114 & 0.288 \\
Malaysia & 0.631 & 0.063 & 2.782 & 4.713 & 3.351 & 10.291 \\
\hline
\end{tabular}

Argentine crisis

\begin{tabular}{llllccc} 
& Argentina & Brazil & Chile & Argentina & Brazil & Chile \\
\cline { 2 - 7 } Argentina & 3.758 & 0.590 & 0.189 & 10.374 & 0.435 & 0.351 \\
Brazil & 1.780 & 2.422 & 0.176 & 2.651 & 3.586 & 0.533 \\
Chile & 0.169 & 0.126 & 0.212 & 0.791 & 0.706 & 0.490 \\
\hline
\end{tabular}

1997 to 19 October 1997 as the precrisis period, and 20 October 1997 to 31 August 1998 as the crisis period. There are 434 total observations, 208 in the precrisis period and 226 in the crisis period. The results can be directly compared with the bivariate example of Forbes and Rigobon (2002), who consider contagion between Hong Kong and Korea and Hong Kong and Malaysia. Again, the crisis period considered here is longer than that of Forbes and Rigobon. In this case it corresponds to the considerable turmoil and repeated attacks on the Hong Kong financial markets leading up to the Russian debt default on 17 August 1998.

As shown in table 1 , the variances in the Asian equity markets increased by a factor of about 5 from the precrisis to the crisis period. There are corresponding increases in the covariances, with the largest increase in correlation between Korean and Malaysian returns (from 0.026 to 0.288 ). The decomposition of the Asian crisis in table 2 shows that in the precrisis period, returns in Korea and Malaysia were almost totally determined by country factors, suggesting opportunities for diversification. During the crisis period, contagion accounts for over 70 percent of total volatility for all three equity markets. The effect of Hong Kong provides the largest impact on Korea (at almost 75 percent of total volatility) and just under 50 percent on Malaysia. There is also a reinforcing linkage from Korea to Hong Kong, accounting for 60 percent of Hong Kong volatility. 
Table 2. Variance Decompositions for the Tequila, Asian, and Argentine Crises Based on the DFGM Estimation (\%)

\begin{tabular}{lllllllll}
\hline & \multicolumn{3}{c}{ Precrisis Period } & & \multicolumn{3}{c}{ Crisis Period } \\
\cline { 2 - 3 } \cline { 5 - 7 } Components & $(1)$ & $(2)$ & (3) & & (4) & (5) & (6) \\
\hline
\end{tabular}

Tequila crisis

World factor

Country factor

\begin{tabular}{cccccccc} 
Mexico & Argentina & Chile & & Mexico & Argentina & Chile \\
\cline { 1 - 2 } \cline { 5 - 7 } 12.882 & 63.424 & 24.773 & & 2.909 & 13.842 & 14.396 \\
87.118 & 36.576 & 75.227 & & 19.673 & 7.983 & 43.715
\end{tabular}

Mexico

Argentina

Chile

Total

Variance

\begin{tabular}{rrrrrc}
- & - & - & - & 75.319 & 34.092 \\
- & - & - & 66.407 & - & 7.797 \\
100.000 & 100.000 & 100.000 & 100.000 & 100.000 & 100.000 \\
1.840 & 1.969 & 0.563 & 11.670 & 16.443 & 1.457 \\
\hline
\end{tabular}

Asian flu

World factor

Country factor

\begin{tabular}{|c|c|c|c|c|c|}
\hline Hong Kong & Korea & Malaysia & Hong Kong & Korea & Malaysia \\
\hline 55.2 & 2.641 & 10.956 & 11.825 & 0.408 & 3.005 \\
\hline 44.706 & 97.359 & 89.044 & 9.560 & 15.036 & 24.426 \\
\hline
\end{tabular}

Origin of contagion

Hong Kong
Korea
Malaysia
Total

Variance

\begin{tabular}{rrrrrc}
- & - & - & - & 74.450 & 49.915 \\
- & - & - & 60.514 & - & 22.653 \\
- & - & - & 18.101 & 10.106 & - \\
100.000 & 100.000 & 100.000 & 100.000 & 100.000 & 100.000 \\
2.238 & 2.045 & 2.782 & 10.794 & 13.114 & 10.291 \\
\hline
\end{tabular}

Argentine crisis

World factor

Country factor

\begin{tabular}{|c|c|c|c|c|c|}
\hline Argentina & Brazil & Chile & Argentina & Brazil & Chile \\
\hline 63.918 & 54.471 & 5.679 & 23.083 & 36.822 & 2.484 \\
\hline 36.082 & 45.529 & 94.321 & 13.030 & 30.777 & 41.249 \\
\hline
\end{tabular}

Origin of contagion

\begin{tabular}{lrrrrrr} 
Argentina & - & - & - & - & 11.959 & 52.612 \\
Brazil & - & - & - & 2.495 & - & 3.655 \\
Chile & - & - & - & 61.392 & 20.442 & - \\
Total & 100.000 & 100.000 & 100.000 & 100.000 & 100.000 & 100.000 \\
Variance & 3.758 & 2.422 & 0.212 & 10.374 & 3.586 & 0.490 \\
\hline
\end{tabular}

5.1.3 The Argentine Crisis: 2001-02 Argentina experienced substantial turmoil in its financial markets in the second half of 2001, leading up to the float of the peso on 2 January 2002. Some background to the crisis is given in de la Torre, Levy Yeyati, and Schmukler (2003). We date the crisis here from 10 July 2001, when the Argentine government formally adopted a zero-deficit rule in order to retain access to international bond markets. In the intervening period between this announcement and the float of the 
Table 3. Alternative Contagion Test Statistics during the Tequila Crisis, $p$-Values in Parentheses

\begin{tabular}{llccccc}
\hline $\begin{array}{l}\text { Host } \\
\text { Country }\end{array}$ & Recipient & & & & & \\
\hline Mexico & Country & DFGM & FR & FR-M & FG & BKS \\
& Argentina & $21.892^{*}$ & -0.723 & 1.700 & $121.972^{*}$ & $8.760^{*}$ \\
& & $(0.000)$ & $(0.765)$ & $(0.192)$ & $(0.000)$ & $(0.003)$ \\
& Chile & 2.524 & 0.022 & 0.074 & $38.139^{*}$ & 0.005 \\
& & $(0.112)$ & $(0.491)$ & $(0.786)$ & $(0.000)$ & $(0.945)$ \\
& Both & $37.858^{*}$ & - & 2.653 & $78.259^{*}$ & $13.033^{*}$ \\
Argentina & & $(0.000)$ & & $(0.265)$ & $(0.000)$ & $(0.000)$ \\
& Mexico & $67.257^{*}$ & -0.833 & $3.205^{*}$ & $16.425^{*}$ & $9.827^{*}$ \\
& & $(0.000)$ & $(0.798)$ & $(0.073)$ & $(0.000)$ & $(0.002)$ \\
& Chile & $4.375^{*}$ & -0.951 & 1.918 & $10.180^{*}$ & $8.250^{*}$ \\
& & $(0.036)$ & $(0.577)$ & $(0.166)$ & $(0.001)$ & $(0.004)$ \\
& Both & $70.152^{*}$ & - & $5.661^{*}$ & $18.742^{*}$ & 0.908 \\
Chile & & $(0.000)$ & & $(0.059)$ & $(0.000)$ & $(0.341)$ \\
& Mexico & $9.974^{*}$ & 0.239 & 0.071 & - & 0.005 \\
& & $(0.002)$ & $(0.405)$ & $(0.791)$ & & $(0.942)$ \\
& Argentina & $2.871^{*}$ & 0.531 & $36.150^{*}$ & - & $8.765^{*}$ \\
& & $(0.090)$ & $(0.298)$ & $(0.000)$ & & $(0.003)$ \\
& Both & $14.257^{*}$ & - & $40.883^{*}$ & - & $12.515^{*}$ \\
& & $(0.001)$ & & $(0.000)$ & & $(0.000)$ \\
& & $101.825^{*}$ & - & $65.378^{*}$ & $101.897^{*}$ & - \\
& & $(0.000)$ & & $(0.000)$ & $(0.000)$ & \\
\hline
\end{tabular}

Note: The FG test for this crisis does not have a local shock for Chile (they are all common shocks), so we cannot test for contagion from Chile. DFGM = Dungey et al. (2003) test; FR = Forbes and Rigobon (2002) test ( $M=$ multivariate); FG = Favero and Giavazzi (2002) test; BKS = Bae, Karolyi, and Stulz (2003) test.

*Indicates the presence of statistically significant contagion at the 10 percent level.

peso were protracted negotiations between Argentina, the U.S. Treasury, and the IMF. In the example here we consider contagion between Argentina, Chile, and Brazil over a crisis period of 9 July 2001 to 3 December 2001, compared with a precrisis period of 9 July 2000 to 8 July 2001. The total sample comprises 366 observations, with 261 in the precrisis period and 105 in the crisis period.

Table 1 for the Argentine crisis shows large increases in both variances and covariances between the precrisis and crisis periods. The biggest increases in correlation are between Argentina and Chile (0.189 to 0.351 ) and Brazil and Chile (0.176 to 0.533). Interestingly, the correlation between Brazilian and Argentinean returns falls marginally (0.590 to 0.435). Table 2 shows that in the precrisis period Argentina and Brazil exhibit similar variance decompositions, with the country factor contributing less than 50 percent in both cases. In contrast, 94 percent of volatility returns in Chile are associated with a country-specific factor. During the crisis period, Argentina and Brazil look different. Contagion contributes nearly two-thirds of Argentina's volatility compared with one-third of Brazil's. The most strik- 
Table 4. Alternative Contagion Test Statistics during the Asian Flu, $p$-Values in Parentheses

\begin{tabular}{|c|c|c|c|c|c|c|}
\hline $\begin{array}{l}\text { Host } \\
\text { Country }\end{array}$ & $\begin{array}{l}\text { Recipient } \\
\text { Country }\end{array}$ & DFGM & FR & FR-M & FG & BKS \\
\hline \multirow[t]{3}{*}{ Hong Kong } & Korea & $\begin{array}{r}158.187^{*} \\
(0.000)\end{array}$ & $\begin{array}{c}-0.295 \\
(0.616)\end{array}$ & $\begin{array}{c}1.175 \\
(0.278)\end{array}$ & $\begin{array}{r}117.582^{*} \\
(0.000)\end{array}$ & $\begin{array}{c}2.210 \\
(0.137)\end{array}$ \\
\hline & Malaysia & $\begin{array}{c}1.574 \\
(0.210)\end{array}$ & $\begin{array}{c}-0.507 \\
(0.694)\end{array}$ & $\begin{array}{c}1.162 \\
(0.281)\end{array}$ & $\begin{array}{r}137.669^{*} \\
(0.000)\end{array}$ & $\begin{array}{r}6.015^{*} \\
(0.014)\end{array}$ \\
\hline & Both & $\begin{array}{r}182.063^{*} \\
(0.000)\end{array}$ & - & $\begin{array}{c}1.968 \\
(0.374)\end{array}$ & $\begin{array}{r}217.451^{*} \\
(0.000)\end{array}$ & $\begin{array}{l}10.019^{*} \\
(0.002)\end{array}$ \\
\hline \multirow[t]{3}{*}{ Korea } & Hong Kong & $\begin{array}{c}45.651^{*} \\
(0.000)\end{array}$ & $\begin{array}{c}-0.315 \\
(0.624)\end{array}$ & $\begin{array}{c}1.518 \\
(0.218)\end{array}$ & $\begin{array}{r}304.902^{*} \\
(0.000)\end{array}$ & $\begin{array}{c}2.146 \\
(0.143)\end{array}$ \\
\hline & Malaysia & $\begin{array}{c}12.085^{*} \\
(0.001)\end{array}$ & $\begin{array}{c}-0.257 \\
(0.601)\end{array}$ & $\begin{array}{c}1.031 \\
(0.310)\end{array}$ & $\begin{array}{r}356.649^{*} \\
(0.000)\end{array}$ & $\begin{array}{c}2.369 \\
(0.124)\end{array}$ \\
\hline & Both & $\begin{array}{r}439.764^{*} \\
(0.000)\end{array}$ & - & $\begin{array}{c}1.872 \\
(0.392)\end{array}$ & $\begin{array}{c}65.402^{*} \\
(0.000)\end{array}$ & $\begin{array}{c}8.517^{*} \\
(0.004)\end{array}$ \\
\hline \multirow[t]{3}{*}{ Malaysia } & Hong Kong & $\begin{array}{c}53.578^{*} \\
(0.000)\end{array}$ & $\begin{array}{r}-0.348 \\
(0.636)\end{array}$ & $\begin{array}{c}6.582^{*} \\
(0.010)\end{array}$ & $\begin{array}{r}146.704^{*} \\
(0.000)\end{array}$ & $\begin{array}{r}6.862^{*} \\
(0.009)\end{array}$ \\
\hline & Korea & $\begin{array}{c}0.773 \\
(0.379)\end{array}$ & $\begin{array}{c}-0.105 \\
(0.542)\end{array}$ & $\begin{array}{c}4.963^{*} \\
(0.026)\end{array}$ & $\begin{array}{c}73.385^{*} \\
(0.000)\end{array}$ & $\begin{array}{c}2.181 \\
(0.140)\end{array}$ \\
\hline & Both & $\begin{array}{c}70.005^{*} \\
(0.000)\end{array}$ & - & $\begin{array}{l}10.765^{*} \\
(0.005)\end{array}$ & $\begin{array}{r}202.745^{*} \\
(0.000)\end{array}$ & $\begin{array}{l}11.145^{*} \\
(0.001)\end{array}$ \\
\hline Joint & & $\begin{array}{r}772.474^{*} \\
(0.000)\end{array}$ & - & $\begin{array}{l}14.357^{*} \\
(0.026)\end{array}$ & $\begin{array}{r}1085.287^{*} \\
(0.000)\end{array}$ & - \\
\hline
\end{tabular}

Note: See note to table 3.

*Indicates the presence of statistically significant contagion at the 10 percent level.

ing result is the apparent reinforcement of contagion effects between $\mathrm{Ar}$ gentina and Chile.

\subsection{Results of Contagion Tests}

Some preliminary information on the data characteristics of the crisis samples is provided in table 6 . The table gives the number of observations in the precrisis and crisis periods for each test, but also gives the exceedances and co-exceedances based on the FG and BKS selection procedures, given in equations (15) and (17).

Three hypotheses are tested. Hypothesis 1 is the null of no contagion among all countries during the crisis period. Hypothesis 2 tests the null of no contagion from one country (the host country) to both other countries in the sample. Hypothesis 3 tests the null of no contagion between two individual countries within the group. The first two hypotheses are examined using the DFGM, multivariate FR, FG, and BKS tests. The third hypothesis can be examined using each of these tests and the FR test.

5.2.1 Contagion during the Tequila Crisis Table 3 provides the results of the contagion tests for the Tequila crisis. (A summary of the results is given in the first part of table 7.) Table 3 reports the results of the DFGM test, the 
bivariate FR test, the multivariate FR test, the FG test, and the BKS test. The left-hand column indicates the host country, from which contagion is sourced, and the second column indicates the country potentially in receipt of contagion. Each cell gives the value of the test statistic with the $p$-value in parentheses. An asterisk $\left({ }^{*}\right)$ denotes evidence of contagion at the 10 percent level, through a rejection of the null of no contagion.

The first result to note is that all tests find strong evidence against the first hypothesis of no contagion within the group (the test statistics are shown in the final row of table 3 ). For the second hypothesis of no contagion from the host country to the other countries there is broad agreement on significant contagion, as shown in the rows labelled "Both" in the table. The null of no contagion for hypothesis 2 is supported in the multivariate FR test for transmissions originating in Mexico and for the BKS test for contagion originating from Argentina. In the case of Chile there are no unique exceedances associated with Chile (see table 6), which is why there are no tests of contagion originating from Chile reported for the FG test.

The results for the tests on the third hypothesis, of no contagion between pairs of countries, provides mixed evidence. The FR test supports the null of no contagion, consistent with results reported in Forbes and Rigobon (2002). The multivariate version of the FR test finds some significant linkages, but fewer than other tests. The difference between the bivariate and multivariate FR tests reflects two things: one, the inclusion of additional variables; and two, the choice of the low-volatility period. The FG and DFGM tests are in agreement in rejecting the null of no contagion in all cases, with the exception being from Mexico to Chile, where the $p$-value for the DFGM test is 0.112. Inspection of table 6 shows that the number of exceedances used in the FG test for Argentina is one. Hence all the results reported for this test in table 3 hinge on the significance of that one observation.

The BKS test provides evidence for contagion from Argentina to the other countries individually, despite the earlier reported lack of contagion from Argentina to other countries jointly in testing hypothesis 2. The BKS test is conducted on the significance of an extreme shock from Argentina (exceedance) on corresponding contemporary extreme shocks in Mexico and Chile (co-exceedance). This explains why there can be significant contagion from one country to other countries individually, but insignificant tests of contagion to both countries simultaneously.

5.2.2 Contagion during the Asian Flu Table 5 shows there is less agreement among the results of the contagion tests for the Asian crisis period. The final row of table 4 again shows that hypothesis 1 , of no joint contagion, is rejected in each case. Under hypothesis 2, the DFGM, FG, and BKS tests reject the null of no contagion emanating from a host country to others in the sample using each country as the host in turn. The multivariate FR test rejects hypothesis 2 only in the case of contagion transmitted from Malaysia.

The FG tests reject the null of no contagion between each pair of countries in testing hypothesis 3 . The DFGM tests agree, with the exceptions 
Table 5. Alternative Contagion Test Statistics during the Argentine Crisis, $p$-Values in Parentheses

\begin{tabular}{|c|c|c|c|c|c|c|}
\hline $\begin{array}{l}\text { Host } \\
\text { Country }\end{array}$ & $\begin{array}{l}\text { Recipient } \\
\text { Country }\end{array}$ & DFGM & FR & FR-M & FG & BKS \\
\hline \multirow[t]{3}{*}{ Argentina } & Brazil & $\begin{array}{c}0.087 \\
(0.768)\end{array}$ & $\begin{array}{c}-1.426 \\
(0.923)\end{array}$ & $\begin{array}{c}16.874^{*} \\
(0.000)\end{array}$ & $\begin{array}{r}181.516^{*} \\
(0.000)\end{array}$ & $\begin{array}{c}16.129^{*} \\
(0.000)\end{array}$ \\
\hline & Chile & $\begin{array}{c}57.110^{*} \\
(0.000)\end{array}$ & $\begin{array}{c}0.221 \\
(0.412)\end{array}$ & $\begin{array}{c}0.279 \\
(0.598)\end{array}$ & $\begin{array}{r}699.079^{*} \\
(0.000)\end{array}$ & $\begin{array}{c}0.001 \\
(0.975)\end{array}$ \\
\hline & Both & $\begin{array}{r}161.182^{*} \\
(0.000)\end{array}$ & - & $\begin{array}{c}17.152^{*} \\
(0.000)\end{array}$ & $\begin{array}{r}562.294^{*} \\
(0.000)\end{array}$ & $\begin{array}{c}10.758^{*} \\
(0.001)\end{array}$ \\
\hline \multirow[t]{3}{*}{ Brazil } & Argentina & $\begin{array}{c}0.999 \\
(0.318)\end{array}$ & $\begin{array}{r}-0.944 \\
(0.827)\end{array}$ & $\begin{array}{c}0.080 \\
(0.778)\end{array}$ & $\begin{array}{r}356.493^{*} \\
(0.000)\end{array}$ & $\begin{array}{c}16.249^{*} \\
(0.000)\end{array}$ \\
\hline & Chile & $\begin{array}{r}2.933^{*} \\
(0.087)\end{array}$ & $\begin{array}{c}2.004^{*} \\
(0.023)\end{array}$ & $\begin{array}{c}22.989^{*} \\
(0.000)\end{array}$ & $\begin{array}{r}29.703^{*} \\
(0.000)\end{array}$ & $\begin{array}{r}4.758^{*} \\
(0.029)\end{array}$ \\
\hline & Both & $\begin{array}{l}16.525^{*} \\
(0.000)\end{array}$ & & $\begin{array}{c}23.327^{*} \\
(0.000)\end{array}$ & $\begin{array}{r}191.042^{*} \\
(0.000)\end{array}$ & $\begin{array}{c}0.001 \\
(0.977)\end{array}$ \\
\hline \multirow[t]{3}{*}{ Chile } & Argentina & $\begin{array}{c}53.718^{*} \\
(0.000)\end{array}$ & $\begin{array}{c}0.376 \\
(0.354)\end{array}$ & $\begin{array}{c}1.822 \\
(0.177)\end{array}$ & $\begin{array}{l}19.338^{*} \\
(0.000)\end{array}$ & $\begin{array}{c}0.001 \\
(0.971)\end{array}$ \\
\hline & Brazil & $\begin{array}{c}1.138 \\
(0.286)\end{array}$ & $\begin{array}{r}1.599^{*} \\
(0.055)\end{array}$ & $\begin{array}{r}19.162^{*} \\
(0.000)\end{array}$ & $\begin{array}{l}15.739^{*} \\
(0.001)\end{array}$ & $\begin{array}{r}4.483^{*} \\
(0.034)\end{array}$ \\
\hline & Both & $\begin{array}{c}68.133^{*} \\
(0.000)\end{array}$ & - & $\begin{array}{c}29.514^{*} \\
(0.000)\end{array}$ & $\begin{array}{c}27.464^{*} \\
(0.000)\end{array}$ & $\begin{array}{r}9.125^{*} \\
(0.003)\end{array}$ \\
\hline Joint & & $\begin{array}{r}225.491^{*} \\
(0.000)\end{array}$ & - & $\begin{array}{c}73.170^{*} \\
(0.000)\end{array}$ & $\begin{array}{r}1453.29^{*} \\
(0.000)\end{array}$ & \\
\hline
\end{tabular}

Note: See note to table 3 .

"Indicates the presence of statistically significant contagion at the 10 percent level.

that no contagion is detected from Hong Kong to Malaysia, or Malaysia to Korea. These differences in the results possibly reflect that the FG assigns a separate parameter value to each exceedance, while in DFGM the contagion is all summarized by a single parameter. The same is true for BKS, where the test of contagion is based on a single parameter. Both the BKS and multivariate FR tests find only limited evidence of contagion between pairs of countries. The bivariate FR tests find no evidence to reject the null of no contagion. The only pair of countries in which all tests, other than the bivariate FR test, agree on rejecting the null of no contagion is from Malaysia to Hong Kong. (A summary of the test results for the Asian flu crisis is provided in the central panel of table 7.)

5.2.3 Contagion during the Argentine Crisis Table 5 reports the evidence for contagion in the Argentine crisis, and is summarized in the final panel of table 7. As with the previous crises examined, hypothesis 1 of no contagion jointly in all countries is rejected by all tests. The tests also reject hypothesis 2 of no contagion from a host country to others in the sample, for each country as the host. The one exception to this is the BKS test, which finds no contagion from Brazil to both Argentina and Chile jointly. This 
Table 6. The Number of Observations Involved in Testing the Significance of Contagion, by Crisis and Test

\begin{tabular}{|c|c|c|c|c|c|}
\hline & \multicolumn{5}{|c|}{ Tests } \\
\hline & DFGM & FR & FR-M & FG & BKS \\
\hline \multicolumn{6}{|l|}{ Tequila effect } \\
\hline Total observations & 197 & 197 & 197 & 197 & 197 \\
\hline Precrisis observations & 143 & 143 & 143 & 143 & 143 \\
\hline Crisis observations & 54 & 54 & 54 & 54 & 54 \\
\hline \multicolumn{6}{|l|}{ Exceedances } \\
\hline Mexico & & & & $6(5)^{a}$ & 10 \\
\hline Argentina & & & & $5(1)^{a}$ & 10 \\
\hline Chile & & & & $3(0)^{a}$ & 10 \\
\hline \multicolumn{6}{|l|}{ Co-exceedances } \\
\hline Mexico and Argentina & & & & 1 & 4 \\
\hline Mexico and Chile & & & & - & 2 \\
\hline Argentina and Chile & & & & 3 & 4 \\
\hline All & & & & - & \\
\hline \multicolumn{6}{|l|}{ Asian flu } \\
\hline Total observations & 434 & 434 & 434 & 434 & 434 \\
\hline Precrisis observations & 208 & 208 & 208 & 208 & 208 \\
\hline Crisis observations & 226 & 226 & 226 & 226 & 226 \\
\hline \multicolumn{6}{|l|}{ Exceedances } \\
\hline Hong Kong & & & & $6(5)^{a}$ & 22 \\
\hline Korea & & & & $7(6)^{a}$ & 22 \\
\hline Malaysia & & & & $7(7)^{a}$ & 22 \\
\hline \multicolumn{6}{|l|}{ Co-exceedances } \\
\hline Hong Kong and Korea & & & & 1 & 4 \\
\hline Hong Kong and Malaysia & & & & - & 5 \\
\hline Korea and Malaysia & & & & - & 4 \\
\hline All & & & & - & \\
\hline \multicolumn{6}{|l|}{ Argentine crisis } \\
\hline Total observations & 366 & 366 & 366 & 366 & 366 \\
\hline Precrisis observations & 261 & 261 & 261 & 261 & 261 \\
\hline Crisis observations & 105 & 105 & 105 & 105 & 105 \\
\hline \multicolumn{6}{|l|}{ Exceedances } \\
\hline Argentina & & & & $6(4)^{a}$ & 18 \\
\hline Brazil & & & & $3(1)^{a}$ & 18 \\
\hline Chile & & & & $5(3)^{a}$ & 18 \\
\hline \multicolumn{6}{|l|}{ Co-exceedances } \\
\hline Argentina and Brazil & & & & 1 & 6 \\
\hline Argentina and Chile & & & & 1 & 2 \\
\hline Brazil and Chile & & & & - & 4 \\
\hline All & & & & 1 & \\
\hline
\end{tabular}

Note: Abbreviations are explained in table 3 note and in text.

annique exceedances are given in brackets. These are the observations that are used in the Faverro and Giavazzi test for contagion. 
result reflects the low number of co-exceedances (two) between Argentina and Chile in the sample, as reported in table 6.

The tests of hypothesis 3 , for no contagion between pairs of countries, produce mixed results. In one case, for contagion from Brazil to Chile, all five tests, including the bivariate FR test, agree on the presence of contagion. The evidence on contagion from Chile presents a mixed picture. On the one hand, all tests but the DFGM test agree on contagion from Chile to Brazil. On the other hand, both the DFGM and FG tests agree on contagion from Chile to Argentina. The results supporting contagion from Chile to Argentina are consistent with the variance decomposition presented in table 3, where just over 60 percent of volatility in Argentinean returns in the crisis period was due to contagion from Chile.

In the case of contagion from Argentina, the multivariate FR, FG, and BKS tests reject the null of no contagion to Brazil, and the DFGM and FG tests reject the null of contagion from Argentina to Chile. The latter result is consistent with the increase in the correlation in returns from the precrisis period to the crisis period for Argentina and Chile reported in table 1 ( 0.189 to 0.351 ). The evidence of contagion from Argentina to Brazil is at odds with the observed decrease in correlation between these returns from the noncrisis to the crisis period ( 0.590 to 0.435$)$.

\subsubsection{Synthesis of Results Table 7 records the number of instances across} tables 3 through 5 in which the null hypothesis of no contagion is rejected using each test in each crisis. Hypothesis 1 represents the joint test of no contagion, and the number of rejections is reported in the final column of table 7. The maximum potential number of rejections is three, and all methods in each sample reject the null of no contagion for the overall test.

Hypothesis 2 represents the test of no contagion from one host country to both other countries in thesample. The maximum potentialnumber of rejections of the null of no contagion is four, the second-to-last column of table 7 shows that at least three tests agree on this in each case (and in each case the test that fails to reject the null of no contagion is the multivariate FR test).

Hypothesis 3 tests for no contagion between pairs of countries. Five tests are run in each case. Table 7 shows the speckled evidence of contagion presented by the tests. Only in the case of contagion from Brazil to Chile do all five tests agree. Most often the bivariate FR test fails to reject the null of no contagion.

Overall, the bivariate FR test appears to be a conservative test, with low power resulting in the test being biased toward a failure to reject the null of no contagion (this is consistent with the results of Billio and Pelizzon 2003). At the other extreme, the FG test tends to find too much evidence of contagion compared with the other results. This is partly the result of the test being a function of just a few outliers in the data, as shown in table 6 . The FR multivariate version of the test does find more evidence of contagion than the bivariate version but not as much as the other multivariate tests. The DFGM test in general yields evidence of contagion that is con- 
Table 7. Corroboration of Evidence across Tests: The Number of Tests That Reject the Null Hypothesis of No Contagion in Each Case

\begin{tabular}{|c|c|c|c|c|c|c|}
\hline Crisis & $\begin{array}{l}\text { Host } \\
\text { Country }\end{array}$ & & $\begin{array}{l}\text { Bivariate } \\
\text { Links }\end{array}$ & & $\begin{array}{l}\text { Host to } \\
\text { Others }\end{array}$ & Overall \\
\hline & & Mexico & Argentina & Chile & & \\
\hline \multirow{4}{*}{$\begin{array}{c}\text { Mexican } \\
\text { crisis }\end{array}$} & Mexico & - & 3 & 1 & 3 & \\
\hline & Argentina & 4 & - & 3 & 3 & 3 \\
\hline & Chile & 1 & 3 & - & 3 & \\
\hline & & Hong Kong & Korea & Malaysia & & \\
\hline \multirow{4}{*}{$\begin{array}{l}\text { Asian } \\
\text { crisis }\end{array}$} & Hong Kong & 一 & 2 & 2 & 3 & \\
\hline & Korea & 2 & - & 2 & 3 & 3 \\
\hline & Malaysia & 4 & 2 & - & 4 & \\
\hline & & Argentina & Brazil & Chile & & \\
\hline \multirow{3}{*}{$\begin{array}{l}\text { Argentine } \\
\text { crisis }\end{array}$} & Argentina & 一 & 3 & 2 & 4 & \\
\hline & Brazil & 2 & 一 & 5 & 3 & 3 \\
\hline & Chile & 2 & 4 & - & 4 & \\
\hline \multicolumn{7}{|c|}{ Possible high } \\
\hline score & & 5 & 5 & 5 & 4 & 3 \\
\hline
\end{tabular}

sistent with the change in the correlation structure and variance decomposition in the data presented in tables 1 and 2. Often the DFGM, FG, and BKS tests are in agreement, particularly in the host-to-others tests. In those cases where the BKS test fails to find contagion but the other tests do, the number of co-exceedances used in identifying contagion is low.

\section{CONCLUSIONS}

This chapter briefly reviews the relationships between four alternative tests for the presence of contagion in financial markets. The four tests considered are the latent factor model of Dungey et al. $(2002,2005)$, the correlation test popularized by Forbes and Rigobon (2002), the dummy-variables approach of Favero and Giavazzi (2002), and the probability-based test of Bae, Karolyi, and Stulz (2003). The main contribution of the chapter is to highlight the potential inconsistencies in tests of contagion arising from the way in which common shocks are modeled, how endogeneity bias is treated, and how crisis-period information is filtered to identify contagion. Each of the tests is applied to common data sets and periods. The tests are applied to daily equity market returns in three distinct crisis periods. The first is the socalled Tequila crisis of 1994-95, where contagion is tested for between Mexico, Argentina, and Chile. The second is the Hong Kong crisis of October 1997, testing for contagion between Hong Kong, Korea, and Malaysia. The final example is the Argentine crisis of 2001-02, where contagion is considered between Argentina, Brazil, and Chile. 
The contribution of this chapter has been to examine how conclusions about the existence of contagion in a particular crisis and group of countries is affected by the methodology used. While there is agreement in the joint tests of contagion, there is little in more specific tests between particular countries: the joint tests reject the null hypothesis of no contagion, but the results are more mixed for pairs of countries, ranging from no contagion at all in the bivariate FR tests to rejection of no contagion between almost all pairs in the endogeneity-corrected FG test. The four tests differ in ways of modeling common shocks, controling for endogeneity, and filters to process crisisperiod information. The next step in this research agenda is to discover how these features affect the finite sample properties and statistical performance of the tests by performing a range of Monte Carlo experiments.

\section{APPENDIX: DATA DEFINITIONS}

All data are from Thomson Financial Datastream.

Argentina: Buenos Aires Merval share price index [AGSHRPRCF]

Brazil: Brazil BOVESPA share price index [BRSHPRCF]

Chile: CL Share price index [CLI62 ... F]

Hong Kong: Hang Seng index [HKSHRPRCF]

Korea: KOSPI share price index [KOSHRPRCF]

Malaysia: Kuala Lumpar SE composite index [MYSHRPRCF]

Mexico: IPC Mexico Bolsa share price index [MXSHRPRCF]

\section{NOTES}

1. The Fisher transformation is used in equation (6) to improve the asymptotic properties of the test (Forbes and Rigobon 2002). For further refinements of this transformation, see Kendall and Stuart (1969, p. 391). This transformation is valid for small values of the correlation coefficients, $\rho_{x}$ and $v_{y}$, and relatively large samples. Problems may arise when very small samples are involved; see Dungey and Zhumabekova (2001), for example.

2. Potential methods for formalizing crisis date selection could be based on statistical procedures allowing for endogenous breaks or the determinant of the change in the covariance matrix (DCC) of Rigobon (2003).

3. The idea consists of simulating a high frequency model (say, hourly) and then sampling the simulated data to coincide with the observed data. A similar approach is used in estimating continuous time models from discrete data; see Gourieroux, Monfort, and Renault (1993).

4. As the model is just identified, the variances reported in table 1 are exactly decomposed into the components listed in table 2.

\section{REFERENCES}

Bae, K.-H., G. A. Karolyi, and R. M. Stulz, 2003, A New Approach to Measuring Financial Contagion, Review of Financial Studies 16, 717-763. 
Baur, D., and N. Schulze, 2003, Coexceedances in Financial Markets: A Quantile Regression Analysis of Contagion, University of Tuebingen Economics Discussion Paper 253.

Berg, A., and C. Pattillo, 1999, Are Currency Crises Predictable? A Test, International Monetary Fund Staff Papers 46, 107-138.

Billio, M., and L. Pelizzon, 2003, Contagion and Interdependence in Stock Markets: Have They Been Misdiagnosed? Journal of Economics and Business 55, 405-426.

de la Torre, A., E. Levy Yeyati, and S. L. Schmukler, 2003, Living and Dying with Hard Pegs: The Rise and Fall of Argentina's Currency Board, Economia: Journal of the Latin American and Caribbean Economic Association 3, 43-99.

Dornbusch, R., Y. C. Park, and S. Claessens, 2000, Contagion: Understanding How It Spreads, World Bank Research Observer 15, 177-197.

Dungey, M., R. Fry, B. González-Hermosillo, and V. L. Martin, 2002, International Contagion Effects from the Russian Crisis and the LTCM Near-Collapse, International Monetary Fund Working Paper 02/74.

__ 2005, Empirical Modeling of Contagion: A Review of Methodologies. Quantitative Finance, forthcoming.

Dungey, M., and V. L. Martin, 2004, A Multifactor Model of Exchange Rates with Unanticipated Shocks: Measuring Contagion in the East Asian Currency Market, Journal of Emerging Markets Finance, 3, 305-330.

Dungey, M., and D. Zhumabekova, 2001, Testing for Contagion Using Correlations: Some Words of Caution, Federal Reserve Bank of San Francisco, Pacific Basin Working Paper PB01-09.

Edison, H. J., 2003, Do Indicators of Financial Crises Work? An Evaluation of an Early Warning System, International Journal of Finance and Economics 8, 11-53.

Eichengreen, B., A. K. Rose, and C. Wyplosz, 1995, Exchange Market Mayhem: The Antecedents and Aftermath of Speculative Attacks, Economic Policy: A European Forum 21, 249-296.

- 1996, Contagious Currency Crisis, National Bureau of Economic Research Working Paper 5681.

Favero, C. A., and F, Giavazzi, 2002, Is the International Propagation of Financial Shocks Non-Linear? Evidence from the ERM, Journal of International Economics 57, 231-246.

Forbes, K. J., and R. Rigobon, 2002, No Contagion, Only Interdependence: Measuring Stock Market Comovements, Journal of Finance 57, 2223-2261.

Glick, R., and A. K. Rose, 1999, Contagion and Trade: Why Are Currency Crises Regional? Journal of International Money and Finance 18, 603-617.

Goldstein, M., G. L. Kaminsky, and C. M. Reinhart, 2000, Assessing Financial Vulnerability: An Early Warning System for Emerging Markets (Institute for International Economics, Washington, D.C.).

Gourieroux, C., A. Monfort, and E. Renault, 1993, Indirect Inference, Journal of Applied Econometrics 8, S85-S118.

Kaminsky, G. L., and C. M. Reinhart, 2003, The Center and the Periphery: The Globalization of Financial Turmoil, National Bureau of Economic Research Working Paper 9479.

Kaminsky, G. L., and S. L. Schmukler, 1999, What Triggers Market Jitters? A Chronicle of the Asian Crisis, Journal of International Money and Finance 18, 537-560.

Kendall, M. G., and A. Stuart, 1969, Kendall's Advanced Theory of Statistics, Volume 1: Distribution Theory (Charles Griffin and Co., London). 
Knif, J., and S. Pynnonen, 1999, Local and Global Price Memory of International Stock Markets, Journal of International Financial Markets, Institutions and Money 9, 129-147.

Lowell, J., C. R. Neu, and D. Tong, 1998, Financial Crises and Contagion in Emerging Market Countries, RAND Working Paper MR-962.

Masson, P. R., 1999, Contagion: Macroeconomic Models with Multiple Equilibria, Journal of International Money and Finance 18, 587-602.

Pericoli, M., and M. Sbracia, 2003, A Primer on Financial Contagion, Journal of Economic Surveys 17, 571-608.

Rigobon, R., 2003, On the Measurement of the International Propagation of Shocks: Is the Transmission Stable? Journal of International Economics 61, 261-283.

Sachs, J. D., A. Tornell, and A. Velasco, 1996, Financial Crises in Emerging Markets: The Lessons from 1995, Brookings Papers on Economic Activity 1996 2, 147-215.

Taylor, M. P., 1987, Covered Interest Parity: A High-Frequency, High-Quality Data Study, Economica 54, 429-438.

Van Rijckeghem, C., and B. Weder, 2001, Sources of Contagion: Is It Finance or Trade? Journal of International Economics 54, 293-308. 


\section{University Library}

\section{- M M N E R VA A gateway to Melbourne's research publications}

Minerva Access is the Institutional Repository of The University of Melbourne

Author/s:

DUNGEY, M.;FRY, R.;GONZALEZ-HERMOSILLO, B.;MARTIN, V.

Title:

A comparison of alternative tests of contagion with applications

Date:

2005

Persistent Link:

http://hdl.handle.net/11343/32482 